\title{
Sexual violence on campus
}

\section{Objectification, awareness- raising and response}

\author{
Marion Paoletti, Suzanne Quintin, \\ Jane Gray-Sadran and Laure Squarcioni
}

\section{Context}

The Bordeaux campus, in the south-west of France, covers an area of several hundred hectares and its buildings are located on different sites around Greater Bordeaux. This study focuses on one specific part of the campus, the surface area of which is shared by the neighbouring towns of Pessac, Talence and Gradignan (PTG), located 15 kilometres from the centre of Bordeaux. The campus is home to several university faculties and Grandes Ecoles: the University of Bordeaux; Bordeaux Montaigne University; Sciences Po Bordeaux; Bordeaux Institut National Polytechnique (a group of engineering schools) and Bordeaux Sciences Agro (Institute of Agricultural Sciences).

Approximately 50,000 people study or work on this vast 235 -hectare campus. For the purpose of this chapter, the PTG campus is divided into two zones: zone 1, where the faculties and schools in social and human sciences are located; and zone 2 , where the science, technology, engineering and mathematics (STEM) faculties and schools are found. More than 60 per cent of students and staff who attend zone 1 are women while in zone 2 men comprise 60 per cent of students and staff from the University of Bordeaux. The campus was built between 1961 and 1970 , to accommodate the growing number of students, following the expansion of higher education in that decade. Its architectural and urban design is typical of the period with long buildings, surrounded by car parks, parks and woodland, far from Bordeaux's city centre and poorly integrated into the adjoining towns. The construction of the campus followed the functionalist ideal of a place specifically dedicated to study and work (Dubet and Sembel 1994). Shops and a cinema were included in the initial plans but were subsequently cancelled by the Ministry of Higher Education. The campus was built under political pressure as there was a need to relocate the students and minimise the cost, based on the idea of a 'pure' study campus: 'green, clean and calm' (Dubet and Sembel 1994, 226). This idea has guided the campus development for years and created an isolated place, linked to Bordeaux city centre by the tram line. This runs through the campus and began operating in 2007, one year after the campus construction was completed. There are three tram stops, one of which has posed a number of safety problems. 
Since 2008, the entire Bordeaux campus has undergone a vast renovation programme by Operation Campus, a development project that falls within the remit of the University of Bordeaux and is jointly financed by the state, the NouvelleAquitaine Regional Council and the urban community of Bordeaux Métropole. The renovation of zones 1 and 2 of the PTG campus began in 2014 and will end in 2022. It is in this context that the gender equality officers, of the different universities and schools located on the PTG campus, brought to the fore the question of recurring reported incidents of sexual aggression, predominantly against young women. These incidents are an unfortunate reality on campus, requiring analysis and solutions that needed to be taken into account in the renovation project, to prevent future assaults. Gender equality officers and colleagues were fully committed to their responsibilities at the University of Bordeaux and Sciences Po Bordeaux. This chapter outlines the process of awareness-raising leading to the proposals submitted for the integration of gender equality into the different planning stages of the renovation of the campus, with lessons learned from this experience. The chapter raises the more general question of how to address the phenomenon of sexual violence on campus. It also illustrates how a concerted prevention campaign against sexual violence can be built and maintained, despite resistance.

Even though there has already been extensive research on the question of sexual violence endured by young women (VIRAGE, ESSIMU), there are, to date, few studies focussing on sexual violence experienced by female students on campus (Day 1994). PTG campus is a public space with a layout of buildings that is perceived to be conducive to the presence of potential sexual predators. This perception is supported by a general feeling of anxiety, fuelled by students' shared stories about their exposure to and experience of sexual violence. There are three halls of residence on the PTG campus and the majority of residents are female students. For women, in particular, going from one place to another on the PTG campus has precipitated feelings of anxiety, especially after dark and at night. The relationship between the built environment and women's fear of assault has contributed to the constitution of fear as a social reality (Koskelka and Pain 2000; Lieber 2008).

\section{Methodology}

The perception of insecurity, related to reported incidents of sexual violence on the PTG campus, was raised with the planners and decision-makers through two research interventions, an online survey and the implementation of safety audits involving walks through the campus to determine areas of perceived insecurity or danger. The methodology of the safety audit was conducted in two stages, in two different contexts. In 2017, the question of sexual violence on the campus was raised by the gender equality officers. In 2019 , when a new series of safety audits was organised, in the area around one of the tram stops where there had been reported incidents of rape and sexual aggression, the specific context of insecurity 
at that time led to the university administration having to face student action in a crisis situation.

The close coordination between the gender equality officers of the different schools and universities on the campus was a determining factor in persuading the planners and decision-makers to take the issue of sexual violence seriously. The political behaviour of students in relation to feminist issues including sexual violence was also highlighted, alongside the challenges that institutions have encountered when engaging the participation of feminist student groups in discussion of these issues.

\section{Researching sexual violence on campus}

Gathering solid, reliable data on sexual violence on campus was essential to the analysis of what is a diffuse phenomenon, a problem that existed but had never been quantified. Such data are particularly useful for raising awareness among students and staff and also of interest to researchers in the wider academic context.

In the first instance, an online survey was carried out by questionnaire, designed by the gender equality officers with the support of Opération Campus, and distributed by email to the entire university community of the PTG campus. The questionnaire included thirty, mainly closed questions with opportunities to make open-ended comments. The aim was to identify the scale and type of sexual aggression experienced by respondents, where it took place on campus and the perceptions of personal safety by staff and students on campus. Data collection took place between April and June 2017 and 4,920 people responded, the majority of whom were students and women: 70 per cent of respondents were students and 28 per cent were staff, 62 per cent of respondents were women, 36 per cent were men. Less than 2 per cent identified as 'other'.

Experience on campus was perceived very differently according to the time of day. Half of respondents stated that they were not comfortable on campus after dark and, unsurprisingly, a request for improved street lighting was frequently expressed in responses. However, this request does not accord with the sustainable development policies of the local authorities, who switch off public streetlights at $1 \mathrm{am}$, and on campus 30 minutes after the arrival of the last tram at 12.30am on weekdays (1.30am on weekends). This is in order to save energy and avoid disturbing animal and insect life. This questions the extent to which the local government's environmental policies conflict with the needs expressed by students and staff in relation to personal safety in public spaces.

Compared to men, women were twice as anxious about their safety (60 per cent versus $30 \%$ ) and this feeling had consequences for the routes taken from one place to another. Two-thirds of all respondents stated that they avoided certain dimly lit areas, half did not come on campus outside office or class hours and onethird declared that they avoided walking alone on campus. The sports fields, along with car parks, were the areas that were most avoided, especially by women. One-quarter of respondents had heard of cases of sexual aggression on campus. 
Knowledge of these cases mainly stemmed from conversation and rumours but also from certain schools that systematically informed staff and students when an incident had occurred.

In order to establish an inventory of the forms of aggression experienced, the following question was asked: 'Have you ever experienced one or more of the following situations on the PTG campus?' and a list of situations was presented. More than one response was possible. Nearly three-quarters of respondents ( 74 per cent, or 3,558 respondents) declared that they had never had to face such situations. In contrast, 26 per cent, or 1,260 respondents, stated that they had experienced one or several of the situations mentioned in Table 6.1.

Table 6.1 Reported incidents on the PTG campus $(n=4,819)$

\begin{tabular}{lcc}
\hline Nature of incident & Number & Percentage \\
\hline Chatted up insistently & 780 & 16 \\
Followed over a long distance & 468 & 10 \\
Insulted & 442 & 9 \\
Confronted by an exhibitionist & 246 & 5 \\
Undergone unwanted physical contact & 235 & 5 \\
Victim of sexual aggression & 12 & 0.2 \\
Victim of rape, or attempted rape & 5 & 0.1 \\
None of these situations & 3,558 & 74
\end{tabular}

Note: The total percentage adds up to more than 100 per cent due to the fact that several choices were possible.

Among the 1,260 people who declared they had experienced sexual aggression, only 36 specified that they knew the attacker. The experience 'chatted up insistently', which can be identified as a form of sexual harassment, was chosen most frequently ( 780 people) and took place mainly between $5 \mathrm{pm}$ and $9 \mathrm{pm}$. 'Followed over a long distance' was cited by 468 people. This phenomenon was said to increase as the day progressed and was at its worst after 9pm. This affected people living on campus twice as much as those who did not. These results were reinforced by the oral testimonies collected during the awareness-raising meetings prior to the safety audits. Female students living in the halls of residence on campus explained that they felt particularly exposed to being followed home after lectures, especially in the evening, and as a result felt uneasy and worried about being attacked. A total of 246 respondents declared that they had already come across an exhibitionist on campus.

Even though the survey provided a much clearer picture of sexual aggression on campus, identifying precise locations proved to be less clear since the incidents occurred over the entire area of the campus and were not concentrated in specific zones. However, the survey did shed light on the universities' lack of knowledge of the problem, since the victims declared that they rarely turned to the prevention services of their university for help (only 62 people reported the incidents to their university) (Table 6.2). 
Table 6.2 Responses to incidents $(n=1,210)$

\begin{tabular}{lcc}
\hline Response & Number & Per cent (\%) \\
\hline I spoke about it to my friends and family & 622 & 51 \\
I spoke about it to a doctor/nurse/psychologist & 14 & 1 \\
I reported the incident to the prevention services of & 62 & 5 \\
$\quad$ my university school & 51 & 4 \\
I reported the incident to the police & 497 & 41 \\
I did not speak about it & 66 & 5 \\
Other & \\
\hline
\end{tabular}

The survey, which constituted the first stage of the awareness-raising and quantification of the problem, enabled an assessment of incidents of which universities were unaware. One of the reasons for this lay in the large number of public stakeholders in charge of security on campus: universities, schools, the city council, local authorities, the students' welfare office, inter-university services responsible for street lighting, security and the planners. None of these had any systematic mechanisms for recording such incidents or for sharing knowledge concerning them. The results of the online survey confirmed, for the first time, that aggressive acts were a recurring problem on a campus, where services were used by a majority of female students $(60 \%)$. This in itself justified the need for the problem to be taken seriously.

The online survey concluded with an open-ended question: 'Do you have anything you would like to add (recommendations, testimonies and so on)?' The 520 respondents who took the time to answer this question provided personal testimonies, expressed their feelings about the problem, criticised the universities' services or made recommendations. The majority of these responses fell into four categories:

1 adapt to the situation (by avoiding certain areas, taking the car, avoiding the campus at night, moving out, learning self-defence techniques);

2 raise awareness (poster campaigns, informing all students);

3 crack down on the problem (by imposing disciplinary sanctions, reporting the offence, taking legal action);

4 make improvements to security installations (railings, gates) or to places where people can meet socially. Improved street lighting was quoted as a top priority.

\section{Identifying campus problem zones}

The next phase of the initiative focused on the safety audits as a pre-requisite to demarcating safe, inclusive, gender-neutral spaces. The audits were undertaken in two phases, in two very different contexts: in 2017-2018 and again in 2019. They consisted of organising group walks in a specific area or neighbourhood, by day 
and night, with the purpose of identifying the physical and social characteristics that contributed to making the location(s) a safe or unsafe place. This method was based on two assumptions: that women were more likely to experience a greater feeling of insecurity in their use of public spaces than in private; and also that women could identify the factors that lead to aggression. Safety walks are a useful tool, especially if they take place at the beginning of an urban development project, to evaluate the safety of a particular geographical place and to raise awareness of potential problem areas. The safety audit concept was developed in 1989 in Toronto by the Metropolitan Action Committee on Violence against Women and Children (Andrew et al 2013) to evaluate the degree of comfort and security that women experience in urban public spaces. Since then, the concept has been used to develop an inclusive urban design project. From a woman's perspective, safety audits are generally undertaken only by women, so that they feel free to express themselves about their fears in a safe environment.

Within the context of the PTG campus renovation, the gender equality officers jointly proposed conducting safety audits. Opération Campus fully supported their request to benefit from their expertise. The methodology for the safety audit was developed from 'A Places Egales' led by a sociologist, Dominique Poggi. It is described as a 'simple yet rigorous' design to analyse the social causes as well as the problems in urban design that lead to insecurity and avoidance strategies. Its stated aim is to make 'recommendations in favour of more inclusive public spaces' (https://aplacesegales.wordpress.com) by mobilising women who are trained as experts to work on the different stages of the safety audit. Given the level of interest expressed by male students and academic colleagues, it was decided that men could be invited to participate in one of the walks.

The first stage involved raising awareness among stakeholders and the public. In March 2017, a steering committee was established to address the issue of sexual violence on campus. Its members included the directors or vice-chancellors of each of the schools and universities, local politicians and Opération Campus. A public meeting was organised and the 30 or so people who attended provided insights into the problems experienced by female students. These included: groups of male youths loitering on campus shouting sexist remarks and insults; female students being followed back to the halls of residence; and the presence of exhibitionists or prowlers. These testimonies illustrated the different ways in which female students experienced one important aspect of residential life on the campus.

The following month, a mapping session was organised to determine two routes for the walks in zone 1 . The aim was to analyse plans of the campus grounds in order to establish the routes. Discussions explored questions such as: 'How do I feel in this particular part of the campus?'; 'Do I feel safe there during the day? At night?'; 'Where do people tend to hang around and what do they do there?' Specific areas were identified on the plans. This was done simply by placing different-coloured stickers on the maps to locate both the problematic places and the zones that everyone agreed were safe. Two walks were then identified for 
the safety audit, each one lasting up to two hours, including stops along the way. These walks took place between May and October 2017, one by day and another by night. A final walk, with the managers of Opération Campus and media, focused on raising their awareness and communicating recommendations. More than 20 people participated on each walk. They were attributed specific roles and everyone was given the opportunity to express themselves. The group observed their surroundings, described how they felt, analysed street signs, considered visibility, street lighting and the availability of public transport. The general state of the grounds and the buildings was also noted as was the frequency of use of specific areas. There was a final group discussion to identify proposals which derived from observations made during the walks.

A summary report and recommendations were published and presented to Opération Campus. The report was officially presented at public meetings on campus and at meetings with decision-makers, including local councillors and civil servants, the director of Opération Campus, student welfare services and university board members. The results were also communicated to students and staff at a meeting in December 2017 during which a female police commander from the Direction of Public Security, French Ministry of the Interior, gave advice on safety and precautionary measures to adopt in public spaces. Whilst this kind of meeting was seen as useful by the majority of those present, it was also met with criticism by some female students who felt that it was not only the responsibility of women to protect themselves, but equally the responsibility of the authorities to make sure the campus was a safe place for all students.

The main priorities were for signposts (the names and locations of the different buildings and services, distances, information to help people find their way around campus), which were deemed non-existent or inaccurate. Numerous pathways needed to be improved with better lighting. Sports facilities were not designed to encourage gender diversity and the pathways leading to sports halls or pitches also needed improved street lighting. Sheltered bicycle parking stands, where some aggressive acts had taken place, needed renovation. There was also a lack of places where students could meet socially. Many embankment slopes needed to be removed and branches of trees pruned to improve visibility. A further suggestion was that tram-stops and halls of residence should be named after famous or important women since all were currently named after men.

These recommendations were taken into account by Opération Campus and integrated into the future renovation programme. The safety audits, together with the online survey contributed to heightening awareness of aggression on campus and mobilising the university community to respond positively to the problem. Perpetrators were seldom prosecuted because victims tend not to report assaults to the universities or the police. The phenomenon had therefore remained largely hidden and ignored, but thanks to the safety audits, this was no longer the case. However, it was not certain that these walks encouraged the decision-makers on campus to coordinate their responses to the question of sexual violence. What did encourage them was when a large group of female students gathered in 2018 
to express their anger, following further incidents of sexual aggression. It was in the context of this crisis that the gender equality officers organised another safety audit in January 2019. This time it took place in zone 2, particularly around a tram stop named Doyen Brus that subsequently became a symbol for publicising sexual violence on campus. Making physical changes to improve campus safety is a long process that is inevitably programmed over several years. The work undertaken to raise awareness and propose solutions was not enough to prevent acts of aggression. However, it did lead to greater transparency in terms of communicating the problem, at the risk of stirring emotions conducive to student mobilisation.

\section{Dealing with emotion and student protest against sexual violence on campus: a new series of walks}

The recurrence of sexual aggression on the PTG campus and, more specifically, the complaint registered following the rape of a female student on 26 November 2018 close to the Doyen Brus tram stop, heightened feelings of insecurity, especially among women, on campus. For the first time, the vice-chancellor of the University of Bordeaux, with the support of the vice-chancellors and directors of the other universities and schools, chose to inform the campus community about this case of rape. This was done by email, and the message also included advice for students and staff, so that they would be in a better position to protect themselves from any future assault. This information, which was widely relayed on social networks, caused a strong emotional reaction. Students took to social networks in protest. This happened within the context of \#MeToo, a movement that symbolises a new wave of feminism (Bertrand 2018). By 13 December 2018, the students had created a private, women-only Facebook page called Les Campusciennes (The Campus Women), which quickly attracted more than 3,000 members. Their aim was to set up a support and discussion platform among female students so that victims could share their experience of aggression and find information about the prevention of sexual and sexist violence (Albenga and Dagorn 2019). Their exchanges on the Facebook group page highlighted the frequency of aggressive acts and the feeling of anxiety among many women on the PTG campus.

The email sent by the universities and schools was fiercely criticised for its advice-giving. Les Campusciennes deemed it guilt-inducing for women. In the wake of the \#MeToo movement, the aim of the protests, which were more outspoken than before, was to develop a narrative of women's experience of insecurity in public spaces, act collectively against sexual and sexist violence and position themselves as the main group that decision-makers would liaise with. Supported by several feminist associations and student unions, they organised a set of noisy collective actions (Boussaguet 2009), with the aim of publicising the issue and gathering more support. In addition to Facebook discussion groups, they organised meetings, conferences and workshops and launched a petition that had a particularly strong impact. Entitled 'For a Real Battle Against Sexual Aggression on the Bordeaux Campus', this petition, launched in December 2018, addressed 
to the vice-chancellors of Bordeaux Montaigne University and the University of Bordeaux, rapidly gained 15,000 signatures. In only a few days, Les Campusciennes had become a media sensation. Numerous national and regional newspapers followed the story.

On the evening of 19 December 2018, the group Nous toutes 33 Etudiantes organised a protest march from Bordeaux Montaigne University to the Doyen Brus tram stop. Several hundred students attended the march, equipped with torches, fairy lights and candles to symbolically 'bring back the light on campus', according to the Nous Toutes 33 press release. The participants of this march expressed their anger through slogans such as 'A well-lit pathway = a rape prevented', 'Stop the carnage, bring back the light', 'I said no, we must warn against aggression' and 'Rape is never the victim's fault'. Their main demands for improved street lighting were similar to the recommendations made during the safety audits of 2017.

The vice-chancellor of the University of Bordeaux responded by bringing together the different groups and individuals to find an immediate response to the crisis and formalise coordination of security on campus. These included Bordeaux Métropole, the town councils, inter-university services, the higher education institutions and Opération Campus. The first meeting, in January 2019, set out an emergency plan for the first two quarters of 2019: the installation of a CCTV camera and the presence of a dog-handler between 8pm and 2am at the tram stop, as well as the general reinforcement of security measures. In the months that followed, the renovation of street lighting and the setting up of the new security commission was undertaken. In the longer term, the creation of an official pathway to replace an unofficial, unlit 300 metre shortcut that students regularly took from the tram stop to the halls of residence was confirmed. In January 2019, in reaction to the media coverage of the events, the vice-chancellors and directors of the universities and schools sent out a second message to the campus community to respond to the students' criticism that there was a rape culture and a climate of fear on campus and to communicate the prevention initiatives that had already been taken or were underway. At the same time, the gender equality officers organised a second series of safety audits, focused on the problem area around the Doyen Brus tram station (zone 2), an area that had not been explored in 2017. Female students and staff spoke of precautions taken to make sure they were never alone on this part of the campus. Students alighted at this stop to walk back to their halls of residence or to the private student flats close by. However, they did not use the official pathways, but instead took shortcuts through fields or woodland which were neither signposted nor lit. The second series of walks was undertaken using the same method as before and, although they led to recommendations for improvement to that area, very few students took advantage of the walks to assert their demands. However, given the previous student protests, interest was expressed by journalists at the first of these walks, which took place at the end of January 2019.

It is worth placing the assertive actions of the students within the wider context of protest in contemporary France. Research has shown that French citizens tend 
to view their institutions with mistrust (Grossmann and Sauger 2017; Rosanvallon 2002). Young people, in particular those who are politically engaged, tend to reject their institutions more strongly than others (Muxel 2010). In the current context, which is marked by a feeling of scepticism and an expression of political radicalisation, institutions like universities are struggling to encourage participation or an interest in their projects. Based on the experience of gender equality officers there is a perception that students in the social sciences tend to be particularly critical of higher education institutions, even more so when they have been trained in gender studies. The context of a new, worldwide reaction against sexual violence was also significant. Additionally, throughout December 2018 and January 2019 the Gilets Jaunes (Yellow Vests), a street protest movement against economic inequality, was at its height. A meeting between a delegation of Gilets Jaunes and the students mobilised around the question of sexual violence on campus took place in December 2018. These contextual elements may partly explain why there was such a weak student mobilisation around the new walks, perceived as a top-down offer from the academic institution, even though protests related to sexual violence on campus had reached an unprecedented scale (Neveu 2011).

The two safety walks, one organised by day and the other by night around the Doyen Brus tram stop, on a route that was planned during the mapping session, led to a series of new recommendations. There was a lack of visibility on this part of the campus due to insufficient street lighting and a total absence of lights in certain areas. Darkness, trees, hilly grounds, dark corners and building sites all limited the possibility for people both to see and be seen. A second issue was the difficulty participants had in finding their way about. Several signs indicated the wrong direction and the majority of pathways had no signs whatsoever. In addition, the participants complained about the absence of a means of calling for help in case of aggression (alarm signals, emergency call stations or phone numbers). A third observation highlighted the lack of services or facilities where students could meet socially: there were no cafés, sports or leisure facilities or picnic tables that could make that part of the campus a more user-friendly place.

The most sensitive area was the unofficial pathway leading from the tram stop to the halls of residence. At the beginning of autumn 2019, Bordeaux Métropole carried out a study to examine the specific problem related to this pathway, and the security commission is currently preparing to set up the emergency plan established in January 2019. The problem of sexual violence on the campus seems to have been taken seriously, even though it runs the risk of being placed within the more general category of 'security issues'. The gender equality officers continue their awareness campaigns and workshops on the theme of sexual and sexist violence through exhibitions, debates and conferences to ensure the functioning of the sexual harassment monitoring units set up in their respective universities. The campus security services were also trained to deal with sexist and sexual violence by the gender equality officer of the University of Bordeaux and the police. 


\section{Conclusion}

Estimated at a cost of $€ 600$ million, the vast planning operation carried out by Opération Campus, due for completion in 2022, has already begun to have a noticeable and positive effect on the PTG campus environment. The atmosphere is more convivial and the planning currently underway in zones 1 and 2 has taken account of the recommendations made during the safety audits. Opération Campus financed and fully supported this project. In doing so, it contributed to raising awareness about sexual and sexist violence throughout the entire campus community. The safety audit has proved extremely useful for collecting information to make recommendations for improvements to the campus. Combined with quantitative data analysis it helped put the problem of sexual violence on the decisionmakers' table. Based on the Bordeaux experience, the Universities of Rennes and Paris Dauphine have since organised safety walks on their campuses.

Actions by feminist groups certainly contributed to accelerating the responses from different stakeholders on PTG campus, something that the first safety audit in 2017 had not succeeded in doing. In this way, their actions were certainly effective. Their initiatives have since become more radical. For example, on 8 March 2019 (International Women's Day) and at the start of the academic year, slogans painted on the walls of Bordeaux Montaigne University and Sciences Po Bordeaux denounced the alleged tolerance of institutions towards sexual harassment by teachers ('Yes! Teachers can also be rapists'). The practice of 'naming and shaming' has also been used. Pressure on institutions to deal with sexual violence has not diminished. On the contrary, it has increased with the help of social networks and in a wider context of political radicalisation across France. Consequently, in addition to the efforts made by the French Ministry of Higher Education, Research and Innovation and the European Union, student protest movements, as well as institutional mobilisation driven by the gender equality officers, have all contributed to pushing the problem of sexual violence higher onto the agenda of university leaders.

\section{References}

Albenga, V. and Dagorn, J. (2019) Après \#MeToo: Réappropriation de la sororité et résistances pratiques d'étudiantes françaises, Mouvements, 3 (99), 75-84, doi:10.3917/ mouv.099.0075

Andrew, C., Canuto, M. and Travers, K. (2013) Le défi d'être, à la fois, local et mondial: Femmes et Villes International, Économie et solidarités, 43 (1-2), 55-69, doi:10. $7202 / 1033275 \mathrm{a}$

Bertrand, D. (2018) L'essor du féminisme en ligne. Symptôme de l'émergence d'une quatrième vague féministe? Réseaux, 208-209 (2), 232-257.

Boussaguet, L. (2009) Les 'faiseuses' d'agenda. Les militantes féministes et l'émergence des abus sexuels sur mineurs en Europe, Revue française de science politique, 59 (2), 221-246, doi:10.3917/rfsp.592.0221 
Day, K. (1994) Conceptualising women's fear of sexual assault on campus: A review of causes and recommendations for change, Environment and Behaviour, 26 (6), 742-765, doi:10.1177/0013916594266002

Dubet, F. and Sembel, N. (1994) Les étudiants, le campus et la ville. Le cas de Bordeaux, Les Annales de la recherche urbaine, 62-63, 225-234, doi:10.3406/aru.1994.1798

Grossman, E. and Sauger, N. (2017) Pourquoi détestons-nous autant nos politiques? Presses de Sciences Po, Paris.

Koskela, H. and Pain, R. (2000) Revisiting fear and place: Women's fear of attack and the built environment, Geoforum, 31 (2), 269-280, doi:10.1016/S0016-7185(99)00033-0

Lieber, M. (2008) Genre, violences et espaces publics. La vulnérabilité des femmes en question, Presses de Sciences Po, Paris.

Muxel, A. (2010) Avoir 20 ans en politique, Editions du Seuil, Paris.

Neveu, C. (2011) Démocratie participative et mouvements sociaux: Entre domestication et ensauvagement? Participations, 1, 186-209, doi:10.3917/parti.001.0186

Rosanvallon, P. (2002) La contre-démocratie. La politique à l'âge de la défiance, Editions du Seuil, Paris. 